\title{
RESENHA
}

\section{QUANDO O NACIONAL É INTERNACIONAL}

DOI: http://dx.doi.org/10.1590/2236-3459/59445

\section{WHEN THE NATIONAL IS INTERNATIONAL}

\author{
Wagner Rodrigues Valente \\ Universidade Federal de São Paulo - campus de Guarulhos, Brasil.
}

\section{$\cos 8$}

MATASCI, Damiano. L'école républicaine et l'étranger. Paris: ENS, 2015.

- oi lançado na França, recentemente, o livro de Damiano Matasci L'école républicaine et l'étranger. Uma obra digna de muitos elogios. De pronto, reconhecida pela Académie des Sciences Morales et Politiques, Institut de France, que conferiu a Matasci o prêmio Louis Cros 2013 por sua pesquisa de doutorado, agora lançada em livro. O autor defendeu a tese em 2012, numa coorientação que reuniu duas universidades: a Universidade de Genebra, na Suíça, e a Escola de Altos Estudos em Ciências Sociais de Paris.

O título ampliado do livro dá-nos uma primeira e precisa ideia de seu conteúdo: L'école républicaine et l'étranger: une histoire internationale des reformes scolaires en France, 1870-1914. O estudo das reformas escolares traz ao leitor o exercício intelectual realizado por Matasci (2015), de análise da circulação e apropriação de modelos culturais constituídos como internacionais que ofereceram substância às reformas do ensino em território francês.

Trata-se de obra de 274 páginas, organizada em três eixos de estudos. O primeiro deles intitulado Circulação de ideias e construção de modelos escolares: a produção de saber sobre os sistemas escolares estrangeiros na França. Tal eixo reúne dois capítulos e 
uma conclusão ao final deles. O primeiro capítulo, Conhecer para melhor aprender: as missões pedagógicas francesas no estrangeiro, e o capítulo 2, Centralizar por melhor conhecer: os circuitos nacionais do saber sobre o estrangeiro, introduzem a temática da busca das referências estrangeiras por representantes nacionais, os missionáriosintelectuais e os seus trajetos para saber sobre o outro. Nos termos do autor este primeiro eixo de discussão permitiu por à luz "os percursos de construção da internacionalidade das reformas escolares francesas do final do século XIX" (p. 89). Essa caracterização aborda a centralidade da primeira parte do livro: destacar a relação que liga os processos de nacionalização do sistema escolar francês à pesquisa permanente de pontos de referência comparativa com os países estrangeiros. Nacionalização e apropriação das propostas de outros países como movimentos complementares e não contraditórios para compreensão dos "processos de fixação do sistema escolar moderno francês no âmbito do Estado-nação” (p. 89).

O segundo eixo de organização da obra de Matasci (2015) intitula-se Da comparação à troca intelectual: os reformadores franceses e o movimento internacional de reforma escolar. Para além do enfatizado no primeiro eixo do livro, a saber, que o âmbito nacional das reformas escolares lança mão da esfera internacional, em processos de apropriação que sedimentam propostas locais, o segundo eixo atém-se a analisar a constituição de espaços privilegiados para a globalização das questões educativas, espaços de comparação internacional em que têm lugar as trocas intelectuais. Esses espaços são tratados em três capítulos - capítulos 3, 4 e 5 - que estruturam esse segundo eixo da obra.

As exposições universais: a entrada em cena dos sistemas escolares é título do capítulo 3. O autor relembra que a educação é um tema tardio nas exposições universais, dado que elas começam em 1851 e somente a partir dos anos 1870 (Viena, 1873; Filadélfia, 1876) a educação tornou-se um verdadeiro objeto de exposição, avaliado por um júri de experts internacionais. E, ainda, a partir da década seguinte, todas as exposições passam a ter seções consagradas aos diferentes graus de ensino. Mais importante é a conclusão de que os espaços destinados à educação nessas exposições, em específico à educação francesa, revelam-se um belo e bom instrumento de legitimação dos projetos republicanos que se beneficiam de um reconhecimento internacional. Para além do caso francês a análise do autor, relativamente aos espaços das exposições universais, mostra que eles constituem-se como centros de informação sobre a evolução dos modos de tratar a educação em termos mundiais. Um espaço de circulação e apropriação de modelos considerados os mais avançados, que põe sob tensão as realizações nacionais e as vontades universalistas de um dado modo de tratar as questões relativas à educação.

O capítulo seguinte à análise das exposições universais, capítulo 4 , atém-se a examinar as implicações, os atores e as temáticas presentes noutro espaço de circulação, de internacionalização das questões relativas à educação: os congressos internacionais. Ele tem por título Os congressos internacionais de ensino: espaços de trocas intelectuais. Favorecidos pelos contatos mantidos em meio às exposições universais, os reformadores dos sistemas de ensino dos diferentes países encontram nos congressos novos espaços e modos de repensar e reformular as suas propostas nacionais. 
As agendas científicas dos congressos são analisadas por Matasci (2015) com o fim de mostrar que elas se articulam com a emergência de ideais e princípios que passam a transformarem-se mais e mais em vontades universais. O autor apresenta uma primeira tabela que revela o crescimento exponencial do número de congressos internacionais partindo da década de 1850, com 23 eventos, e chegando a 1910 com 258 congressos. Sobre as problemáticas que têm lugar nesses encontros o autor menciona que o tema da infância aparece em congressos importantes, consagrados não exclusivamente à educação, mas, também, à família, à higiene e à proteção social. As análises dessas problemáticas permitiu a pesquisadores contemporâneos identificar o processo de emergência progressiva de uma cultura comum sobre a infância.

No mesmo capítulo o autor apresenta outras tabelas para a análise dos congressos, especificando o seu estudo, agora, em termos dos eventos internacionais consagrados ao ensino. Matasci (2015) mostra que no período compreendido entre 1876 e 1910 tais congressos ocorrem paralelamente às exposições universais e um grande número deles é realizado concomitante às exposições e que esses eventos "constituem plataformas de discussão e de comparação, espaços de elaboração e de expressão de uma demanda social, que reúne um público internacional de especialistas composto de administradores, de pedagogos e de professores de diferentes graus de ensino" (p. 123). Dessa forma, essas reuniões constroem modos de pensar a educação nacional por meio do estabelecimento de redes internacionais. A realização desses eventos põe em cena o que o autor caracteriza como "a dialética dos congressos: especificidades nacionais e cultura escolar internacional" (p. 134).

Encerrando os estudos do segundo eixo de organização do livro há o capítulo 5 , intitulado Um momento 1900? A virada organizadora do internacionalismo. No dizer do autor o capítulo "estuda as diferentes tentativas de reagrupamento internacional no domínio da instrução pública, numa época em que o processo de internacionalização da vida social e científica europeia se intensifica consideravelmente" (p. 147). Trata-se, com efeito, de estudar o nascimento e constituição dos bureaux internationaux como instituições que organizam o processo de internacionalização, que é posto em marcha nas últimas décadas do século 19. Entidades cujo fim é solidificar estruturas dedicadas à discussão e às trocas internacionais relativas à educação. A virada organizadora do século 20, como menciona o autor, faz frente às inúmeras tentativas fracassadas de constituição de espaços permanentes de internacionalização, ensaiadas nas décadas anteriores.

Uma das conclusões das mais importantes do livro, considerado até este ponto em dois terços de seu desenvolvimento, refere-se à originalidade no trato metodológico trazido por Matasci (2015). Ele nos mostra que as seções escolares das exposições universais e os congressos internacionais de ensino constituem ponto de partida para análise dos processos mais amplos e complexos que se referem à circulação de ideias pedagógicas e de modelos escolares na Europa ocidental. Sua análise vai de encontro ao trato comparativo tradicional e posiciona o pesquisador no âmbito do regime de circulação, alargando o processo investigativo para muito além das fronteiras nacionais.

Por fim, tem-se o terceiro e último eixo organizador da obra. E, nesta parte final, o autor dedica-se a aplicar, a utilizar toda a discussão anterior, todo o ferramental de análise teórico-metodológica trazido junto com vasta bibliografia de apoio e citação de 
casos empíricos, para evocar o caso francês. O título desse eixo é $A$ reapropriação do internacional: os usos do saber sobre os sistemas escolares estrangeiros na França. Seu desenvolvimento sustenta-se em dois capítulos: $A$ leis escolares e o ensino primário francês no contexto internacional, capítulo 6 , e $A$ recepção de um modelo escolar: a Alemanha e o ensino secundário francês (1865-1902), capítulo 7.

O ensino primário francês tratado no capítulo 6 aborda o desenvolvimento e evolução desse grau de ensino situando-o no contexto internacional. Para além do destaque a temas como introdução da gratuidade escolar, obrigatoriedade do ensino e laicidade, no início dos anos 1880, juntam-se o estudo de modelos escolares estrangeiros que exercem pressão na conjuntura nacional francesa, em face da onda internacional de reformas. Tal conjuntura leva à análise das condições e repercussões da construção da ideia de um atraso escolar da França em termos internacionais.

O capítulo 7 dedica-se à análise dos usos e reapropriações do saber vindo de outros países no âmbito do ensino secundário, num momento em que o ensino secundário francês atravessa uma profunda crise, segunda metade do século 19. Neste caso as apropriações do modelo alemão revelam um processo que poderia ser descrito como "uma sutil mistura de fascinação e repulsa pela fórmula encontrada por esse país para o ensino secundário" (p. 169).

De fato, a obra de Matasci (2015) inaugura novas perspectivas para a história da educação vista pelo prisma de uma história internacional. Para além de teorizar sobre essas possibilidades, o livro L'école républicaine et l'étranger analisa casos concretos das reformas escolares francesas agora compreendidas sob a luz internacional. Para nós, brasileiros, de modo surpreendente, é possível com a obra de Matasci (2015) promover um descentramento. Sempre tivemos em conta o caráter tão nacional, tão fechado em si mesmo da história francesa, da história da educação francesa. Categorias como internacionalidade e processo de internacionalização utilizadas na análise das reformas escolares francesas trazem nova luz à operação historiográfica contemporânea que podem auxiliar as pesquisas brasileiras sobre as mudanças da educação em nosso país.

\section{Referências}

MATASCI, Damiano. L'école républicaine et l'étranger. Paris: ENS, 2015.

WAGNER RODRIGUES VALENTE é professor livre docente do Departamento de Educação da Escola de Filosofia, Letras e Ciências Humanas da Universidade Federal de São Paulo - campus de Guarulhos.

Endereço: Rua do Rosário, 382 - 07111-080 - Guarulhos - SP - Brasil.

E-mail: wagner.valente@unifesp.br.

Recebido em 9 de outubro de 2015.

Aceito em 30 de novembro de 2015. 